\title{
La Seguridad en la Producción de Alimentos en la Granja: Buenas Prácticas Agrícolas y Buenas Prácticas de Manejo - Salud e Higiene de los Trabajadores ${ }^{1}$
}

\author{
Federico G. Caro, Alexandra Chang, Renée Goodrich-Schneider, y Keith R. Schneider ${ }^{2}$
}

\section{Introducción}

Las Buenas Prácticas Agrícolas (BPA) y Buenas Prácticas de Manejo (BPM) abarcan los procedimientos generales que los productores, empacadores y procesadores de frutas y verduras frescas deben seguir para garantizar la seguridad de sus productos. Las BPA son usadas antes de la cosecha (es decir, en el campo), mientras que las BPM se utilizan luego de la cosecha, incluyendo el embalaje y envío. Esta hoja informativa aborda las prácticas de cosecha relacionadas con el saneamiento en el campo. Hay otras siete hojas informativas del Servicio de Extensión de Florida acerca de la "Inocuidad de los Alimentos en la Granja." Esta serie se concentra en aspectos específicos del programa de BPA y cómo se relacionan con los cultivos y las prácticas de la Florida.

\section{Los Riesgos Microbianos}

El contacto entre los productos frescos y la materia fecal ha sido históricamente la causa mayor de las enfermedades transmitidas a través del consumo de alimentos. Los microrganismos patógenos se pueden encontrar en los empleados, tanto si tienen una enfermedad infecciosa, una herida abierta o falta de higiene básica. Los trabajadores en el área de alimentos deben comprender y practicar un nivel de higiene adecuado o corren el riesgo de contaminar en forma no intencional los productos, el agua y los demás trabajadores. Los granjeros deben reconocer y establecer prácticas agrícolas que reduzcan al mínimo el riesgo de contaminación entre productos frescos y fuentes de contaminación microbiana.

\section{Normas Generales}

El Gobierno Federal regula las normas de salud e higiene de los empleados durante el manejo pre y pos cosecha de los productos. El estatuto 21, Parte 110.10 del Código de Regulaciones Federales (CFR), describe las disposiciones generales relativas a la higiene de los trabajadores en las plantas de producción de alimentos (1). Estas pautas se pueden adaptar a otras áreas de la producción de alimentos, incluyendo los campos agrícolas, el transporte y en las operaciones de pequeña escala como por ejemplo puestos ambulantes en la calle. Además, la Ley de Seguridad y Salud en el CFR enumera las normas que el personal de supervisión debe seguir para proteger la salud de los empleados $(2,3)$.

En respuesta y reconocimiento de los problemas crecientes de seguridad alimentaria, la Ley de Modernización Para la Inocuidad de los Alimentos fue aprobada por el Congreso

1. The English version of this document is FSHN10-10/FS158 Food Safety on the Farm: Good Agricultural Practices and Good Handling Practices - Worker Health and Hygiene. Este documento es FSHN12-10s, uno de una serie del Departamento de Ciencia de los Alimentos y Nutrición Humana, Servicio de Extensión Cooperativa, IFAS de la Universidad de Florida. Publicación: febrero de 2013. Ciencia de los Alimentos y Nutrición Humana, Servicio de Extensión Cooperativa, IFAS de la Universidad de Florida, Gainesville, FL 32611-0370. Por favor, visite nuestro sitio web EDIS en http://edis.ifas.ufl.edu/.

2. F. G. Caro, BS., técnico; A. Chang, estudiante de posgrado; R. M. Goodrich-Schneider, PhD, profesora asociada, y K. R. Schneider, PhD, profesor asociado; todos del Depto. de Ciencia de los Alimentos y Nutrición Humana, Servicio de Extensión Cooperativa, IFAS de la Universidad de Florida, Gainesville, FL 32611-0370.

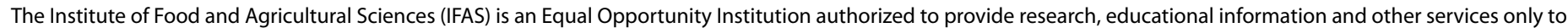

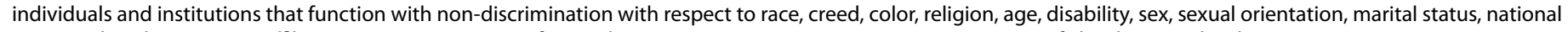
origin, political opinions or affiliations. U.S. Department of Agriculture, Cooperative Extension Service, University of Florida, IFAS, Florida A\&M University Cooperative Extension Program, and Boards of County Commissioners Cooperating. Nick T. Place, Dean 
y firmada por el Presidente en Enero del 2011. La nueva ley exige a las empresas a implementar un programa de seguridad alimentaria que minimice significativamente los riesgos asociados a las enfermedades transmitidas por alimentos. Tomar medidas inmediatas para aplicar buenas prácticas agrícolas de saneamiento en el campo beneficia a las empresas y aumenta la seguridad de los productos en general.

\section{Como Controlar Riesgos Posibles}

Las Buenas Prácticas Agrícolas (BPA) son fundamentales para reducir los riesgos potenciales de contaminación en los alimentos. La Administración de Alimentos y Fármacos de EE.UU. (FDA) identificó que la capacitación de los empleados y la promoción de buenas prácticas de higiene como las áreas más importantes para fomentar un manejo salubre de los alimentos (4).

\section{Salud e Higiene Personal}

Las siguientes Buenas Practicas Agrícolas (BPA) se deben aplicar para asegurar que todos los empleados que trabajen con productos frescos cuiden de su salud e higiene personal, ya sea si estén directamente en contacto con el producto o no.

- Establezca un programa de capacitación - Asegúrese de que todos los empleados entiendan conceptos básicos sobre la sanidad e higiene atendiendo a programas de entrenamiento con instrucción uno-a-uno, con demostraciones sobre la técnica adecuada de lavado de manos, etc. El nivel de comprensión, el seguimiento y la profundidad de la capacitación depende de las responsabilidades y obligaciones de los trabajadores. Ponga carteles cerca de las instalaciones de lavado de manos para reforzar los procedimientos apropiados de lavado de manos. Asegúrese de que todos los empleados nuevos reciban capacitación antes de comenzar a trabajar, y que todos los empleados sean capacitados al menos una vez al año o al comienzo de cada temporada de empaque. Se deben establecer controles de rutina para asegurar el cumplimiento de estos requisitos.

- Familiarizarse con los signos y síntomas típicos de las enfermedades infecciosas es crucial - excluya a empleados que presenten signos o síntomas de una enfermedad cuando interactúan directa o indirectamente con los productos frescos. Ejemplos de agentes patógenos que pueden causar enfermedades infecciosas a través de los alimentos son la Salmonella, la Shigella, el Escherichia coli O157: H7 y el virus de la hepatitis A, sólo para nombrar algunos. Los síntomas más comunes de las enfermedades transmitidas por los alimentos son fiebre, diarrea y vómito. Si muestran síntomas, instruya a sus empleados para que notifiquen a un supervisor antes de comenzar a trabajar. En algunos casos, se les deberá prohibir a los empleados trabajar con productos frescos hasta que su salud mejore.

- Proteja las heridas - No permita que los empleados trabajen con productos frescos o equipo si tienen una lesión, como una infección de la piel o una herida que no se pueda cubrir por completo. Llagas abiertas deben cubrirse con una venda impermeable.

- Considere otras alternativas de buenas prácticas de higiene: guantes desechables, en combinación con el lavado de manos pueden ser una herramienta de higiene eficaz si se usan correctamente, evitando la propagación de agentes patógenos. Se deberá utilizar un par de guantes nuevo después de comer, fumar, o usar el baño. También luego de la manipulación de materiales que no sean productos frescos, o en cualquier momento en el que los guantes sean dañados o contaminados. Si se usan guantes reutilizables, deben ser desinfectados antes de regresar a trabajar. Considere la instalación de grifos automáticos y dispensadores de toallas de papel para evitar la recontaminación después de lavarse las manos.

- Implemente un código de vestuario: Los empleados deben usar ropa limpia, uniformes y/o delantales, los cuales se deben quitar antes de utilizar el baño. Otros hábitos que pueden minimizar la contaminación de los productos a través de los trabajadores son mantener las uñas cortas, no usar joyas, el uso de gorras o redes para cubrir el cabello, y no llevar objetos personales en los bolsillos.

- Todos los visitantes deben obedecer buenas prácticas de higiene - Asegúrese de que los inspectores, clientes y otros visitantes en la granja, empacadora, o en el área de transporte respeten las prácticas de higiene establecidas siempre que entren en contacto con los productos frescos.

\section{Capacitación}

Las normas sanitarias marcadas por la Ley de Seguridad Ocupacional y Salud deben ser señaladas en la capacitación para los trabajadores en el área de las frutas y verduras frescas (2,3). A continuación se encuentran algunas sugerencias de instrucción.

- La importancia de mantener buena higiene - Los empleados deben entender que la mala higiene personal puede afectar su salud y la de los consumidores del producto 
fresco que manejan. Prácticas antihigiénicas pueden causar enfermedades en los trabajadores y el público en general.

- La importancia de lavarse las manos - Varios agentes patógenos que causan enfermedades se encuentran frecuentemente en las heces. Lavarse bien las manos antes de trabajar y después de usar el baño es fundamental para reducir el riesgo de contaminación de la cosecha.

- La importancia de una técnica buena de lavado de manos - Enseñe a los trabajadores cómo lavar las manos con eficacia incluyendo las partes expuestas de los brazos. La técnica apropiada requiere frotarse las manos rigurosamente para desalojar las bacterias, utilizando jabón y agua caliente, limpiarse debajo de las uñas y entre los dedos. Finalmente se deben enjuagar y luego secar las manos con una toalla de papel desechable o un secador de aire. El lavado de manos debe durar al menos 20 segundos.

- La importancia de utilizar los baños - Instruya a los trabajadores para que usen las instalaciones sanitarias y así prevenir la contaminación de los campos, la cosecha, otros trabajadores y los suministros de agua. Se deben designar áreas específicas para otras actividades de los empleados, como comer, beber, fumar, recreos, y el almacenamiento de sus pertenencias.

\section{Operaciones "Coseche Usted Mismo" Puestos en la Calle}

Los agricultores que venden directamente a los clientes o que permiten a los clientes a cosechar ellos mismos en el campo deben considerar las siguientes buenas prácticas de higiene.

- Promover buenas prácticas de higiene, por ejemplo instalando estaciones de lavado de manos para los clientes en el campo.

- Facilitar el uso de baños limpios, debidamente suministrados, y convenientes para los clientes.

- Promover buenos hábitos de manipulación / procesamiento tales como alertar a los clientes para que laven los productos frescos antes de consumirlos.

\section{Referencias}

1. Código de Regulaciones Federales. 2010a. Buenas Prácticas de Manufactura en la fabricación, el embalaje, o almacenamiento de alimentos. Título 21, Parte 110.
Washington, DC: EE.UU. Administración de Alimentos y Fármacos (FDA), la Oficina del Registro Federal.

2. Código de Regulaciones Federales. 2010b. Normas de salud ocupacional y seguridad: servicios sanitarios. Título 29, Parte 1910.141, Subparte J. Washington, DC: EE.UU. Administración de Alimentos y Fármacos (FDA), la Oficina del Registro Federal.

3. Código de Regulaciones Federales. 2010c. Las normas sobre seguridad e higiene para la agricultura: sanidad en el campo. Título 29, Parte 1928.110. Washington, DC: EE.UU. Administración de Alimentos y Fármacos (FDA), la Oficina del Registro Federal.

4. Administración de Alimentos y Fármacos (FDA). 1998. Guía para reducir al mínimo el riesgo microbiano en frutas y verduras frescas. Washington, DC Departamento de Salud y Servicios Humanos de la FDA. Disponible en:http://www.fda.gov/Food/GuidanceComplianceRegulatoryInformation/GuidanceDocuments/ProduceandPlanProducts/UCM064574. Accessed Mar 13, 2011. 